\title{
DESDE FUERA. UNA FILOSOFÍA PARA EUROPA
}

\author{
From Outside. A Philosophy for Europe \\ Bruno Vendramin \\ Universidad de Barcelona \\ brunovendraminn@gmail.com
}

Reseña de: ESPOSITO, Roberto (2018). Desde fuera. Una filosofía para Europa.

Buenos Aires: Amorrortu, pp. 288.

Desde fuera. Una filosofía para Europa tiene por objetivo pensar el presente del continente en el marco de los graves problemas que lo asolan: los flujos migratorios y el terrorismo islámico, la recesión económica y las pretensiones de separación de algunos espacios (Brexit es el caso paradigmático). Según el filósofo napolitano, estamos ante una crisis de carácter biopolítico, por el inescindible vínculo que existe entre política, vida y muerte. Visto este panorama, las explicaciones de la economía, la sociología o la politología no alcanzan. Pareciera que la reflexión filosófica puede abrir pasajes inéditos y creadores -en particular, la biopolítica- que ayuden a identificar la tarea europea en el mundo global venidero: "El destino de nuestro continente, de manera similar al del resto del mundo, se juega en el margen incierto que, en la implicación directa entre la política y la vida biológica, separa una biopolítica afirmativa de una crisis tanatopolítica de dimensiones desconocidas." (p. 12).

El interés de Esposito -de ahí el título del texto- es mirar el continente no autorrepresentativamente y centrado en sí mismo (como lo han varias hecho varias filosofías y, sobre todo, por la corriente que denomina, en la introducción y el primer capítulo, "el dispositivo de la crisis", ideado en las primeras décadas del siglo XX por Valéry, Husserl y Heidegger. En líneas generales, sostuvieron que a Europa le acechaba una enfermedad moral y espiritual de carácter terminal, más bien, una crisis eminentemente metafísica, por lo que para curarla se necesitaba regresar al origen olvidado, es decir, Grecia y la filosofía), sino desde el afuera: "lo exterior siempre ilumina lo interior, y no a la inversa" (p.15). Para esto, se apoya en tres grandes pasajes desterritorializadores $-y$ que, consecutivamente, desarrolla en el capítulo segundo, tercero y cuarto: la German Philosophy, la French Theory y el Italian Thougth. Estos tres momentos ponen en entredicho el constitutivo e histórico vínculo entre Europa y la filosofía. Son giros geográficos y biográficos, a la vez que filosóficos y políticos. 
En primer lugar, la German Philosophy: desde 1930 a 1950, intelectuales alemanes desembarcan -exiliados- en los Estados Unidos: Fromm, Lowenthal, Arendt, y los representantes de la Escuela de Fráncfort: Adorno, Horkheimer, Marcuse. Estos pensadores se convierten en ciudadanos estadounidenses, comienzan a dar clases en universidades norteamericanas y producen sus más fecundas obras en inglés. Es ilustrativo lo que escribió Horkheimer en esos años: "América, y en especial Estados Unidos, es el continente en el cual es posible continuar con la vida científica". Ahora bien, además de las circunstancias biográficas, el afuera es definido por razones teóricas: viene dado por el fenómeno de lo "social", esto es, distintos saberes -política, economía, arte y psicoanálisis- penetran de lleno en el discurso filosófico. Discursos externos obtienen un rango central en el pensamiento. Estos discursos irrumpen críticamente en la filosofía; ésta ya no se concibe de manera autónoma y autorreferencial. La crítica -y, en particular, el concepto de negación- hacen expulsar la filosofía fuera de sí. Un ejemplo que confirma esta tesis es el caso del psicoanálisis: todos los autores de la teoría crítica alemana leyeron minuciosamente a Freud, y después de dicha lectura la filosofía alemana no fue la misma.

El segundo momento del desplazamiento hacia el afuera es el de la French Theory: el ingreso de la filosofía francesa desde los años 70 en los campus universitarios estadounidenses. Los nombres -convertidos en verdaderas stars con un éxito de difusión extraordinario-son conocidos: Derrida, Deleuze, Foucault, Lyotard, Baudrillard, Barthes. La singularidad de la French Theory lo constituyó la "literalización" de la filosofía. La escritura se convierte en el objeto principal del quehacer filosófico. La teoría -que toma su forma concreta con la escritura- se reflexiona a sí misma: ella misma se da sus propias normas y presupuestos. Su "elemento peculiar estriba precisamente en la ausencia de presupuestos teóricos a favor de una práctica de escritura que dicta, ella misma, sus reglas" (p. 135). El momento álgido de este movimiento es la deconstrucción derrideana. Ahora bien, lo que le interesa señalar a Esposito es cómo el carácter literario de las obras de los autores de la French Theory fue causa y efecto, precisamente, de la "neutralización de la filosofía", escritura que "no niega ni afirma", que "abandona toda tonalidad crítica" y que "termina por extraviar toda confrontación con lo real" (p. 18). Así pues, los principales intereses de la teoría francesa son la lingüística, el análisis del discurso y sus contextos, los cultural studies y la literatura comparada. En este caso, el afuera está constituido por la escritura (para Derrida) y por la exterioridad del pensamiento (para Foucault, que critica fuertemente la tradición que hizo del pensar una actividad interna, autoconsciente, sobre todo en el texto El pensamiento del afuera, de junio de 1966).

El último momento hacia el afuera que marca Esposito es el Italian Thought. Varios factores filosóficos y geográficos son los que lo generaron: en primer lugar, el agotamiento del modelo deconstruccionista en Estados Unidos y en el panorama filosófico internacional. En segundo lugar, nace ligado a la noción de biopolítica. Es así que en el cruce entre la deconstrucción (Derrida, con matriz heideggeriana) y la biopolítica (Foucault, con matriz nietzscheana), nace el pensamiento italiano, produciéndose un "desplazamiento de intereses desde el ámbito del lenguaje hacia el horizonte de la vida." (p. 175). Con sus orígenes en la década del sesenta con el operaismo de Tronti -aunque 
su genealogía se puede rastrear en Maquiavelo y Vico, Gramsci y Gentile-, el Italian Thought presenta dos aristas: una, la reflexión sobre la biopolítica; y otra, la crítica de la teología política. En cuanto a la primera, la filosofía italiana contrae una deuda con Foucault, que fue el primero en esbozarla en los años 70 en los cursos impartidos en el Collège de France, mas fue un proyecto que dejó desarticulado e incompleto. Los autores italianos retoman el trayecto foucaultiano y lo utilizan para sus propios intereses filosóficos: Esposito para las categorías inmunidad y comunidad, Agamben para develar el trasfondo teológico-económico del pensamiento occidental y para la crítica al derecho, Negri para pensar la economía política y la posibilidad de prácticas emancipadoras en el siglo XXI. Así estaríamos, según Esposito, en presencia de un biological turn.

La especificidad de la filosofía italiana -y que, al mismo tiempo, constituye su afueraestá dada por el fenómeno de lo político. Lo que define al pensamiento italiano "es la relación, históricamente significativa, con un proceso colectivo que trasciende los límites de lo filosófico y de lo teórico, para instalarse en las dinámicas y en los conflictos políticos" (p. 189). Si la teoría crítica alemana hizo hincapié en lo social y en la negatividad, y la filosofía francesa en la escritura basada en lo neutro, el italiano lo hace en lo político. Específicamente, en la postulación de una biopolítica afirmativa -con sus máximos exponentes en Agamben, Negri y el mismo Esposito- que pretende afirmar "su propia subjetividad de forma directa, no como oposición a algo más." (p. 190). Aquí Esposito incluye su propio aporte filosófico, conjugando las dos categorías centrales que viene trabajando hace años: inmunitas y communitas. Para él, es preciso lograr la "desactivación de los aparatos de inmunización negativa y de activación de nuevos espacios comunes" (p. 218). Ahora bien, la política está signada por el conflicto: "en la filosofía italiana prevalece una concepción bipolar de la competencia entre fuerzas" (p. 202). Inscribiéndose en la tradición realista de la política -la que tiene sus antecedentes en Tucídides y Nietzsche, Weber y Schmitt-, el conflicto es constitutivo de la política, lo que fue históricamente neutralizado, excluido y silenciado del canon de la filosofía política (a través de Hobbes, Rosseau, Kant y Hegel).

Por otro lado, el otro aspecto que caracteriza al Italian Thought es su intento de pensar la vida fuera de la tradición teológica-política de Occidente. Retomando los trabajos de Schmitt y su célebre tesis de que "todos los conceptos significativos de la moderna teoría del Estado son conceptos teológicos secularizados", los filósofos italianos han buscado, a través de distintas operaciones e interpretaciones de lectura, desactivar el lenguaje teológico de la política y de la economía, entendiendo no ya a la secularización de la Modernidad como su disolución "sino como la transmutación del núcleo teológico en el mundo moderno", (p. 220), ya que la teología política se muestra como "la figura milenaria que asumió la metafísica desde el momento en que las religiones monoteístas colmaron nuestro espacio de pensamiento." (p. 230). Desde la perspectiva de Esposito, escapar de la tradición teológico-política es destruir la metafísica que "piensa lo positivo solo como resultado de la negación de su contrario. Si se reflexiona sobre esto, toda categoría política moderna -soberanía, propiedad, libertad- es el producto contrastante de otra elaborada solamente para ser negada." (p. 203). Por ejemplo, en Hobbes el estado 
civil es el producto de eliminar el estado de naturaleza, así como en Locke la propiedad privada se hace a costa de privatizar los espacios comunes. Esposito reveló el funcionamiento del nudo bipolar de las categorías políticas modernas Esposito en su último libro Politica e negazione. Per una filosofia affermativa.

El libro de Esposito constituye un valioso aporte para la filosofía política actual en su vertiente continental, porque, al tiempo que constituye una apuesta por una biopolítica afirmativa, debate con muchos autores vivos de la filosofía europea: alemanes, como Habermas y Grimm; franceses, como Nancy, Balibar, Gauchet y otros; e italianos, con los que mantiene una cercanía biográfica y comparten intereses filosóficos comunes: Negri, Agamben, Cacciari, Marramao, Galli, Vattimo. Asimismo, reconstruye y describe con claridad expositiva -esto sólo vale para el lector especializado en filosofía, ya que el libro es denso teóricamente, sumado a que maneja, como lo viene haciendo desde sus primeros libros, un lenguaje excesivamente abstracto- las principales líneas de la filosofía continental del siglo XX, las que reagrupó en tres grandes grupos: la German Philosophy, la French Theory y el Italian Thought. De hecho, de la fusión y el intercambio de estas líneas teóricas Esposito llega a una de sus tesis principales: "una filosofía de Europa, o para Europa, como reza el subtítulo de este libro, no puede nacer más que del cruce entre sus tradiciones de pensamiento." (p. 22), la cual desarrolla en el último capítulo, "Una filosofía para Europa."

En el último capítulo presenta sus sugerencias político-filosóficas para la Europa actual: la construcción de un "popolo europeo", una "potencia civil", de carácter heterogénea y plural. Retomando la tesis maquiaveliana de que las clases dominantes -en la actualidad, representadas en las altas finanzas globales- buscan oprimir al pueblo y el pueblo busca no ser oprimido, una potencia civil sólo puede generarse desde la confrontación entre estas dos clases -el desarrollo de esta división lo hace en el último punto del libro, bajo el título "Los dos pueblos de Europa". Los intereses populares deben predominar sobre los "grandes". Sólo del conflicto puede crearse un nuevo orden, una nueva unidad. Aquí converge su pensamiento con la tradición conflictual del Italian Thoguth. Sólo de esta división fundamental y "cuando se produzca una verdadera alianza entre los estamentos populares que forman la gran mayoría de los pueblos europeos, podrá Europa encontrar la motivación profunda de su propia unión." (p. 25). Así pues, esas "masas ingentes que se multiplican en las plazas de medio mundo" -pensemos, rápidamente, en el Movimiento del 15-M o Movimiento de los Indignados en España en 2011, el Occupy Wall Street en Estados Unidos, el Nuit Deboit en Francia, o las jornadas de diciembre del año 2001 en Argentina, las asambleas populares que se reunieron en las calles de Buenos Aires bajo el lema "que se vayan todos"- hacen tambalear el sistema democráticorepresentativo clásico, empujándolo hacia sus confines, a su afuera, dejando al desnudo el agotamiento del paradigma estatal. La unificación de Europa sólo se realizará si las multitudes que habitan sus calles consiguen unificarse y lograr eso que denomina "potencia civil". Este "popolo europeo" no "nacerá de tratados o acuerdos. No será el resultado de largas mediaciones entre gobiernos", "no será fruto de acuerdos entre cúpulas", sino que, en el medio de la división constitutiva de la política, este proceso de 
unificación "ya no responderá a los mandos de la máquina teológico-política que aprisiona nuestras vidas, sino que trabajará para su desmantelamiento también a través de las categorías que el pensamiento italiano le ha confiado a la filosofía europea como su efecto más intenso." (p. 282).

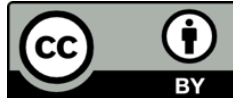

